\title{
Effect of different storage condition on physiological weight loss and cooking quality of brown rice
}

\author{
ANKIT KUMAR* AND V.K. TIWARI
}

Department of Post harvest Process and Food Engineering, Jawaharlal Nehru Krishi Vishwa Vidyalya, JABALPUR (M.P.) INDIA Email:jggankit@gmail.com

*Author for Correspondence

Research chronicle : Received : 02.02.2017; Revised : 06.05.2017; Accepted : 19.05.2017

\section{SUMMARY :}

The physiological weight loss and cooking quality of four month stored brown rice at 12 per cent, 14 per cent and 16 per cent moisture contents (w.b.) were stored in different indigenous storage structures (mud bin, jute bag and polypropylene bag) at prevailing environmental conditions such as weight loss in percentage and cooking index (CI) of brown rice during storage were studied for single variety of paddy (Sugandha). It was found that weight loss percentages increased with number of storage days. The physical weight loss observed in polypropylene bag at the end of four month was 4.80, 5.33 and 6.44 per cent at 12,14 and 16 per cent moisture content, respectively. While in mud bin was $4.98,5.86$ and 7.12 per cent and in jute bag 5.22, 6.55 and 8.00 per cent at 12,14 and 16 per cent moisture content, respectively. While studying cooking qualities of brown rice, it was observed that cooking time reduces with advances in storage period. In polypropylene bag cooking time reduces to ( 65 seconds), followed by mud bin ( 50 seconds) and jute bag ( 42 seconds). Cooking time was no significant change observed at different moisture contents. However, the maximum cooking index was found in polypropylene bag followed by mud bin and jute bag in all moistures levels.

KEY WORDS : Brown rice, Weight loss percentage, Cooking characteristics, Indigenous storage structure, Moisture content, Ageing

How to cite this paper : Kumar, Ankit and Tiwari, V.K. (2017). Effect of different storage condition on physiological weight loss and cooking quality of brown rice. Internat. J. Proc. \& Post Harvest Technol., 8 (1) : 18-23. DOI: 10.15740/HAS/IJPPHT/8.1/18-23. 